\title{
SPECTROPHOTOMETRIC STUDY OF THE CHARGE TRANSFER COMPLEXATION OF SOME AMINO ACID DERIVATIVE DRUGS AS ELECTRON DONORS WITH 7,7,8,8-TETRACYANOQUINODIMETHANE
}

\author{
Sheng Yun $\mathrm{Li}^{1 *}$, Qiao Lin Guo ${ }^{1}$, Wen Yuan ${ }^{1}$, Yu Cui Hou ${ }^{1}$ and Li Ming Du² \\ ${ }^{1}$ Department of Chemistry, Taiyuan Normal University, Taiyuan, Shanxi 030001, P.R. China \\ ${ }^{2}$ Analytical and Testing Center, Shanxi Normal University, Linfen, Shanxi 041004, P.R. China
}

(Received February 25, 2009; revised August 28, 2009)

\begin{abstract}
Charge transfer (CT) complexes of some drugs of amino acid derivatives, such as carbocysteine, aminobutyric acid, and levodopa, as electron donors with 7,7,8,8-tetracyanoquinodimethane (TCNQ) as electron acceptor have been studied. The spectra obtained for carbocysteine/TCNQ, aminobutyric acid/TCNQ, and levodopa/TCNQ systems show the maximum absorption bands at wavelengths of 422, 415, and $417 \mathrm{~nm}$, respectively. The formation of such complexes was also confirmed by infrared measurements. The stoichiometry of the complexes was found to be 1:1 between the donor and the acceptor. The possible reaction mechanisms were explored. The thermodynamic standard reaction quantities of the complexes between donors and acceptor were estimated. Different variables affecting the reaction were carefully studied and optimized. At the optimum reaction conditions, Beer's law was obeyed in a concentration limit of $1-30,1-10$, and $2-50 \mu \mathrm{g} \mathrm{mL} \mathrm{m}^{-1}$ for carbocysteine, aminobutyric acid, and levodopa, respectively. The limits of detection ranged from 0.3 to $0.8 \mu \mathrm{g}$ $\mathrm{mL}^{-1}$. The developed methods could be applied successfully for the determination of the studied compounds in their pharmaceutical dosage forms with a good precision and accuracy compared to official and reported methods as revealed by $t$ - and $F$-tests.
\end{abstract}

KEY WORDS: Amino acid derivative, Drug, 7,7,8,8-Tetracyanoquinodimethane (TCNQ), Charge transfer complex, Spectrophotometry

\section{INTRODUCTION}

Charge-transfer (CT) complexes are formed by interaction between electron donors and electron acceptors. CT complexation is important phenomenon in biochemical and bioelectrochemical energy transfer process [1]. The CT reaction has been widely studied in recent years. Many drugs are easy to determine by spectrophotometry based on stable CT complexes formed.

Carbocysteine, $\gamma$-aminobutyric acid and levodopa are attributed to amino acid derivatives, which are widely used as drugs for mucolytic, resuming brain cells, treatment of Parkinson's disease, and may be chemically named as $(2 R)$-2-amino-3-[(carboxymethyl)sulfanyl]propanoic acid, $\gamma$-amino-butyric acid, and 3-hydroxy-(-)-3-(3,4-dihydroxyphenyl)-L-alanine, respectively. The methods of analysis for carbocysteine and levodopa have been introduced in the pharmacopoeia [2-8], but till date no analytical procedure for aminobutyric acid has been reported in the pharmacopoeia.

Various spectrophotometric methods $[9,10]$ have been reported for the determination of certain amino acid derivatives, such as carbocysteine, $\gamma$-aminobutyric acid, levodopa by CT complexes formation with $p$-benzoquinone and chloranil. In addition, several methods have been reported for their determination, such as fluorimetry [11-13], capillary electrophoresis [1417], chromatographic [5, 18-21] and titrimetric [2-4, 6-8] methods. The titrimetric methods are laborious, less sensitive and time consuming. The capillary electrophoresis and chromatographic methods generally require complicated equipment, provision for use and disposal of solvents, labor-intensive sample preparation procedure, and personnel skilled in chromatographic techniques.

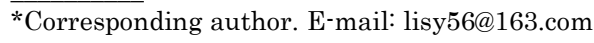


TCNQ is a strong electron acceptor and has been used for the determination of electron donors such as norfloxacin [22], cephalosporins [23], adrenergic blocking agents [24], etc. A new spectrophotometric method for determination of studied drugs in the visible region was reported in this paper through CT complexation with TCNQ having been satisfactorily applied to the determination of these drugs in pharmaceutical formulations and bulk drugs.

\section{EXPERIMENTAL}

Apparatus

A Cary300 UV-Vis spectrophotometer (Varian, USA) was used for the absorbance measurements, using $10 \mathrm{~mm}$ path-length quartz cells. An infrared spectrometer IMPACT- 410 (Nicolet, USA) was used for recording the infrared (IR) spectrum. The $\mathrm{pH}$ was measured on a 210 precise acidometer (Hanna, Italy).

\section{Reagents}

All chemicals and solvents used were of analytical reagent grade. The Britton-Robinson buffer solution was prepared by adjusting $0.04 \mathrm{M} \mathrm{CH} \mathrm{COOH}_{3} \mathrm{H}_{3} \mathrm{BO}_{3}$ and $\mathrm{H}_{3} \mathrm{PO}_{4}$ mixture to $\mathrm{pH} 9.0$ using $0.2 \mathrm{M}$ of $\mathrm{NaOH}$ solution. TCNQ (Sigma Chemical Co., USA) was prepared as $1 \mathrm{mg} \mathrm{mL}^{-1}$ in acetone. The solution was found to be stable for at least 1 week at $4{ }^{\circ} \mathrm{C}$. The drug standard samples of carbocysteine, aminobutyric acid, and levodopa were kindly provided by Chinese National Institute for the Control of Pharmaceutical and Biological Products. Stock standard solution of $1 \mathrm{mg} \mathrm{mL}^{-1}$ was prepared by dissolving studied standard drug samples in water and slight heating as needed. Working standard solutions were prepared by accurately diluting stock standard solution with water.

\section{Pharmaceutical formulation}

The following available commercial preparations were analyzed: (1) carbocysteine tablets (Baiyunshan Pharmaceutical Factory, Guangzhou, China), labelled to contain $250 \mathrm{mg}$ carbocysteine per tablet; (2) aminobutyric acid tablets (Huanghai Pharmaceutical Co. Ltd., Shanghai, China), labelled to contain $250 \mathrm{mg}$ aminobutyric acid per tablet; and (3) levodopa tablets (Fuda Pharmaceutical Co. Ltd., Shanghai, China), labelled to contain $250 \mathrm{mg}$ levodopa per tablet.

\section{General procedure}

A suitable amount of drug solutions was pipetted into a $10 \mathrm{~mL}$ volumetric flask, then $2.0 \mathrm{~mL}$ of TCNQ solution was added, and the solution was diluted to volume with $\mathrm{pH} 9.0$ of BrittonRobinson buffer solution and mixed thoroughly. The solution was thermostated at $60 \pm 0.5{ }^{\circ} \mathrm{C}$ of water bath for $20 \mathrm{~min}$. After rapidly cooling, the absorbencies of CT complexes of carbocysteine, aminobutyric acid, and levodopa with TCNQ were measured at 422, 415 and 417 $\mathrm{nm}$ against a blank solution, respectively. The calibration graph was constructed in the same way with standard working solutions of known concentrations. The amount of studied drug was computed from corresponding calibration graph. 


\section{Analysis of pharmaceutical formulations}

The contents of 20 tablets of each drug (weighed accurately) were pulverized carefully. An amount of the powdered equivalent to the average weight of the tablet was weighed accurately and transferred into a $250 \mathrm{~mL}$ calibrated flask, dissolved in water and slightly heated, swirled and sonicated for $3 \mathrm{~min}$; the solution was diluted to volume with water. The first $20 \mathrm{~mL}$ of the filtrate was discarded, a suitable amount of the solution of the continued filtrate was diluted accurately with water to prepare working solution. Then the analysis was made according to the general procedure described above.

\section{RESULTS AND DISCUSSION}

\section{Absorption spectra}

The absorption spectra of the reaction products between TCNQ and studied drugs are shown in Figure 1. The spectra obtained for carbocysteine/TCNQ, aminobutyric acid/TCNQ, and levodopa/TCNQ systems show the new maximum absorption bands at wavelengths of 422,415 and $417 \mathrm{~nm}$, respectively, which are not due to the absorption of any of the reactants and considered to be results of CT complex formation between the investigated drugs and TCNQ. The new, low energy absorptions observed in solutions containing both a donor and an acceptor have been described by Mulliken [25] as charge transfer transitions involving the excitation of an electron on the donor to an empty orbital on the acceptor. These drugs can be determined colorimetrically by the formation of complexes with TCNQ. The absorbance of each complex was measured at its maximum wavelength. Investigations were carried out to establish the most favorable conditions for the charge-transfer formation. The influence of some variables on the reaction has been tested as follows.

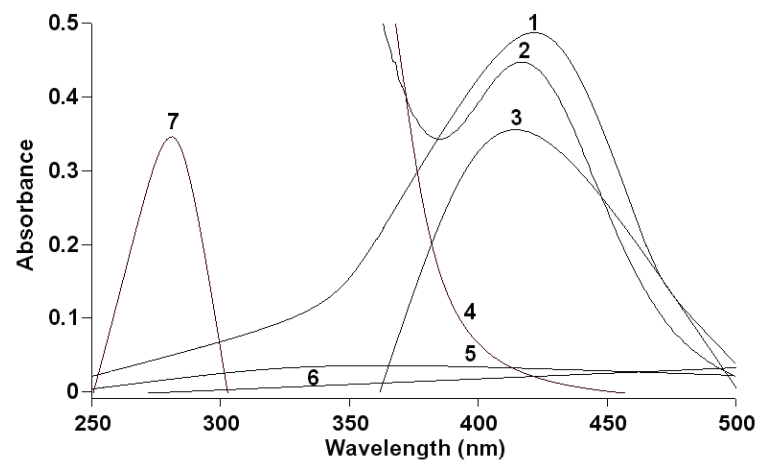

Figure 1. Absorption spectra of the drugs, TCNQ and CT complexes in $\mathrm{pH} 9.0$ of BrittonRobinson buffer solution at $60 \pm 0.5^{\circ} \mathrm{C}$ (in water bath after heating for $20 \mathrm{~min}$ ): 1 , carbocysteine $\left(11 \mu \mathrm{g} \mathrm{mL}^{-1}\right)$-TCNQ $\left(200 \mu \mathrm{g} \mathrm{mL}^{-1}\right) ; 2$, levodopa $\left(35 \mu \mathrm{g} \mathrm{mL}^{-1}\right)$-TCNQ $\left(200 \mu \mathrm{g} \mathrm{mL}^{-1}\right) ; 3$, aminobutyric acid $\left(2 \mu \mathrm{g} \mathrm{mL}^{-1}\right)$-TCNQ $\left(200 \mu \mathrm{g} \mathrm{mL}^{-1}\right) ; 4$, TCNQ (200

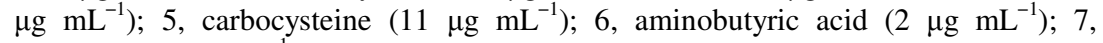
levodopa $\left(35 \mu \mathrm{g} \mathrm{mL}^{-1}\right)$.

\section{Effect of solvent}

Absorption spectral characteristics of the CT complexes of studied drugs with TCNQ in different solvents were compared. The studied solvents involved water, methanol, ethanol, 
acetone, acetonitrile and dimethylsulphoxide. Among these solvents, the most intense absorption was obtained in water. Other solvents (ethanol, acetone, acetonitrile or dimethylsulfoxide) were unsuitable due to limited solubility of the concerned drugs. Water, as solvent, gave satisfactory results.

\section{Effect of reaction temperature and time}

Effect of reaction temperature on the absorption of the CT complexes was studied in the range of 20 to $80^{\circ} \mathrm{C}$ on a water-bath for 0 to $60 \mathrm{~min}$. The suitable temperature and time for obtaining maximum absorbance were carried out at $60{ }^{\circ} \mathrm{C}$ for $20 \mathrm{~min}$. The CT complexes were stable at room temperature for at least $2 \mathrm{~h}$.

\section{Effect of pH of working solution}

The absorption spectra of the color product-CT complexes in working solutions of varying $\mathrm{pH}$ values (8.0-12.0) were recorded in order to select the optimum $\mathrm{pH}$ (Figure 2). The spectral measurements in the visible region show an increase in the absorbance with the increase of $\mathrm{pH}$ of working solution at the specific wavelength till $\mathrm{pH} 8.5$. The absorbance was almost stable between $\mathrm{pH} 8.5$ and 10.0. At $\mathrm{pH}$ more than 10.0, the absorbance immediately decreased with the increase of $\mathrm{pH}$ of working solution. So the optimum $\mathrm{pH}$ value of working solution was taken at 9.0. Coagulation, which might result in high error, occurred in the studied reaction systems at $\mathrm{pH}$ less than 8.0.

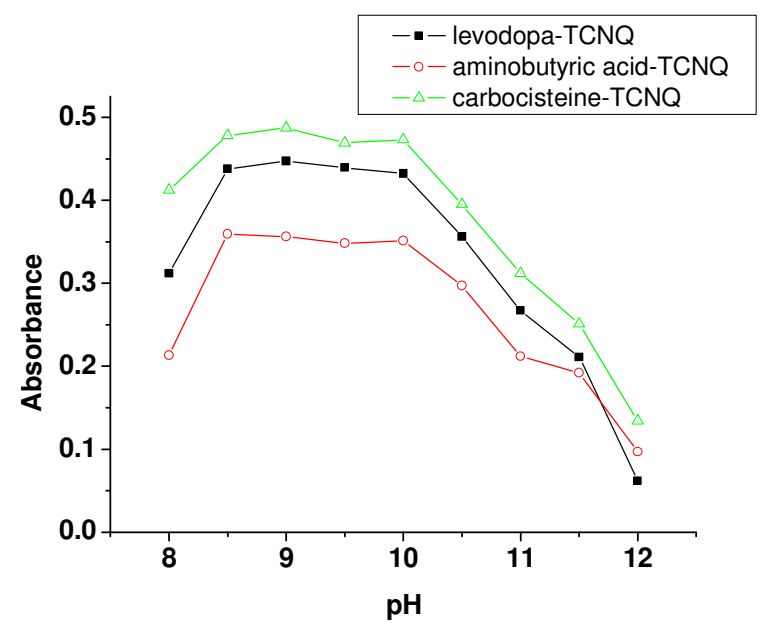

Figure 2. Effect of the amount of $\mathrm{pH}$ on the absorbance of CT complexes at $60 \pm 0.5{ }^{\circ} \mathrm{C}$ (in water bath after heating for $20 \mathrm{~min})$ [carbocysteine $\left(11 \mu \mathrm{g} \mathrm{mL} \mathrm{m}^{-1}\right)$; levodopa $(35 \mu \mathrm{g}$ $\left.\mathrm{mL}^{-1}\right)$; aminobutyric acid $\left(2 \mu \mathrm{g} \mathrm{mL}{ }^{-1}\right)$; TCNQ $\left.\left(200 \mu \mathrm{g} \mathrm{mL}^{-1}\right)\right]$.

\section{Effect of TCNQ concentration}

The influence of CT reagent concentration was studied in the range 100-400 $\mu \mathrm{g} \mathrm{mL} \mathrm{mL}^{-1}$. Experiment indicated that $200 \mu \mathrm{g} \mathrm{mL}^{-1}$ of TCNQ concentration is enough for each compound. 
Investigations on the structure of the CT complexes

TCNQ is a strong $\pi$-electron acceptor; $n-\pi$ or $\pi-\pi$ charge transfer complexes have been reported for determination of many compounds [26]. Studied drugs have one electron rich amino group, which may form $n-\pi$ charge-transfer complexes with TCNQ at the same time [10]. These drugs form complexes probably through the lone pair of electron donated by the $\mathrm{N}$ atom in the amino group ( $n$-electron donors) to TCNQ ( $\pi$-electron acceptor). So, CT complexes can be formed with these drugs. When TCNQ was added to the studied drug solutions, the drug solutions with TCNQ cause an immediate change in the absorption spectrum with new characteristic bands at 422, 415 and $417 \mathrm{~nm}$ for carbocysteine, aminobutyric acid, and levodopa, respectively. The appearance of the new spectral bands in the visible region was the evidence for the possible CT complex formation of the type $n-\pi$ complexes between the studied components and TCNQ. The formation of such complexes was also confirmed by IR measurements. The majority of infrared measurements on such CT complexes have been concerned with the shifts in the vibrational frequencies of donors or acceptors. Decreases in the vibration frequency of a particular band have been used as an evidence for a particular site of a CT interaction [27]. The IR spectrum of TCNQ showed strong bands at 2221,1540 , and $860 \mathrm{~cm}^{-1}$ corresponding to $\mathrm{v}_{\mathrm{C} \equiv \mathrm{N}}$, aromatic $\mathrm{v}_{\mathrm{C}=\mathrm{C}}$ and 1,4-disubstituted benzene stretching, respectively. These bands were shifted in the spectra of the complexes with the investigated compounds (Table 1).

Table 1. IR frequencies of TCNQ and its CT complexes with studied drugs.

\begin{tabular}{|l|l|l|l|}
\hline Compounds & $\nu \mathrm{C} \equiv \mathrm{N}$ & $\nu \mathrm{C}=\mathrm{C}$ & $\delta \mathrm{C}-\mathrm{H}$ \\
\hline TCNQ & 2221 & 1540 & 860 \\
\hline Carbocysteine-TCNQ & 2185 & 1512 & 824 \\
\hline Aminobutyric acid-TCNQ & 2183 & 1508 & 801 \\
\hline Levodopa-TCNQ & 2191 & 1520 & 842 \\
\hline
\end{tabular}

Stoichiometry of the complexes was determined by Job's method of continuous variations, in which master solutions of equimolar concentrations of the donors and acceptor were used in this experiment, and it was found to be 1:1 for each drug with TCNQ. Further support was observed in the straight line method which can be used as a qualitative mean for the determination of the stoichiometry ratio of the donor and acceptor in the complex. This ratio is likely to engender owing to the presence of the nitrogen atom acting as an electron drawing group in the molecule of studied drugs. The nitrogen atom in amino group has more electron density and less sterically hindered. So, $n-\pi$ CT complexes are formed (Figure 3 ).

The association constants for the interaction of each compound with TCNQ were estimated according to the Benesi-Hildebrand Equation when the concentration of acceptor is excess enough to regard $\left[A_{0}\right]>>\left[D_{0}\right][28]$ :

$$
\frac{\left[A_{0}\right]}{A^{\mathrm{AD}}}=\frac{1}{\varepsilon^{\mathrm{AD}}}+\frac{1}{K_{\mathrm{CT}} \varepsilon^{\mathrm{AD}}} \times \frac{1}{\left[D_{0}\right]}
$$

where $\left[A_{0}\right]$ and $\left[D_{0}\right]$ are the total concentrations of the acceptor and donor, respectively, $A^{\mathrm{AD}}$ is the absorbance of the complex at the $\lambda_{\max }, \varepsilon^{\mathrm{AD}}$ the molar absorptivity of the complex, and $K_{\mathrm{CT}}$ is the association constant of the complex $\left(\mathrm{L} \mathrm{mol}^{-1}\right)$. From the previous equation, on plotting the values of $\left[A_{0}\right] / A^{\mathrm{AD}}$ versus $1 /\left[D_{0}\right]$, straight lines were obtained (Figure 4 ), from which the association constants and correlation coefficients were obtained (Table 2). 


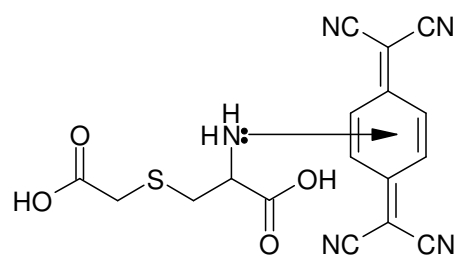

(1)<smiles></smiles>

(2)<smiles></smiles>

(3)

Figure 3. The structure of three amino acid derivatives-TCNQ CT complexes: (1) carbocysteineTCNQ CT complex; (2) aminobutyric acid-TCNQ CT complex; (3) levodopa-TCNQ CT complex.

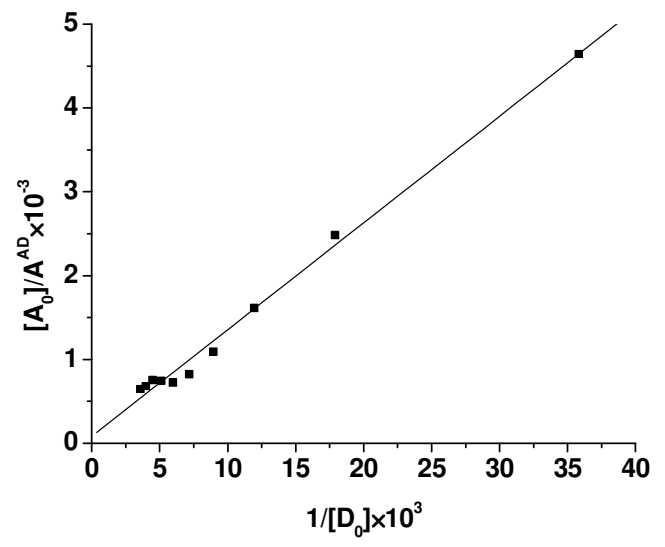

Figure 4 . The curve of $\left[A_{0}\right] / A^{\mathrm{AD}}$ versus $1 /\left[D_{0}\right]$ in carbocysteine $\left(11 \mu \mathrm{g} \mathrm{mL} \mathrm{L}^{-1}\right)$-TCNQ $(200 \mu \mathrm{g}$ $\mathrm{mL}^{-1}$ ) system of $\mathrm{pH} 9.0$ at $60 \pm 0.5^{\circ} \mathrm{C}$ (in water bath after heating for $20 \mathrm{~min}$ ).

Bull. Chem. Soc. Ethiop. 2010, 24(1) 
Table 2. Association constants of the complexes between donors and acceptor $\left(60^{\circ} \mathrm{C}\right)$.

\begin{tabular}{|l|l|l|l|}
\hline Parameters & Carbocysteine-TCNQ & Aminobutyric acid-TCNQ & Levodopa-TCNQ \\
\hline$\lambda(\mathrm{nm})$ & 422 & 415 & 417 \\
\hline$K_{\mathrm{CT}}$ Association constant & 630 & 4750 & 942 \\
\hline Correlation coefficient $(r)$ & 0.9961 & 0.9995 & 0.9984 \\
\hline
\end{tabular}

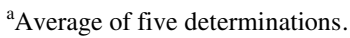

$\Delta G^{\circ}$ values of the complexes are calculated from Gibbs free energy of formation according to the relationship:

$$
\Delta G^{\circ}=-R T \ln K_{\mathrm{CT}}
$$

where $\Delta G^{\circ}$ is the free energy of the CT complexes, $R$ the gas constant $\left(8.314 \mathrm{~J} \mathrm{~mol}^{-1} \mathrm{~K}^{-1}\right), T$ the temperature in Kelvin, and $K_{\mathrm{CT}}$ is the formation constant of donors-acceptor complexes $\left(\mathrm{L} \mathrm{mol}^{-1}\right)$.

The thermodynamic standard reaction quantities $\left(\Delta H^{\circ}\right.$ and $\left.\Delta S^{\circ}\right)$ of the complexes between donors and acceptor were estimated from the temperature dependence of the association constant by plotting $\ln K_{\mathrm{CT}}$ versus $1000 / T$ [29].

For the studied systems, there is no evidence for the deviation from the linearity of the plot of $\ln K_{\mathrm{CT}}$ versus 1000/T over the investigated temperature range (Figure 5).

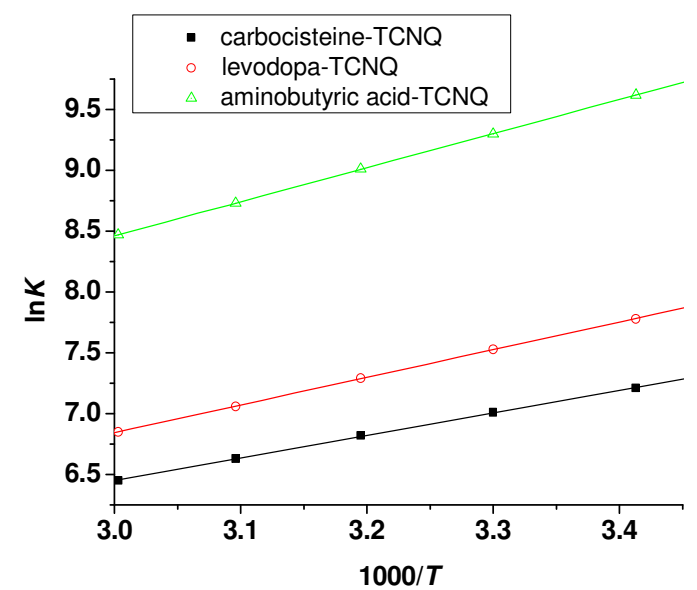

Figure 5. Relation between $\ln K_{\mathrm{CT}}$ and 1000/T K for CT complex of carbocysteine-TCNQ, aminobutyric acid-TCNQ and levodopa-TCNQ.

The parameters thus obtained are represented in Table 3, and these values show that complexation is thermodynamically favored.

Table 3. Thermodynamic parameters of the complexes between donors and acceptor.

\begin{tabular}{|l|c|c|c|}
\hline Parameters & Carbocysteine-TCNQ & Aminobutyric acid-TCNQ & Levodopa-TCNQ \\
\hline$\Delta G^{\circ}$ Free energy $\left(\mathrm{kJ} \mathrm{mol}^{-1}\right)$ & -17.8 & -23.4 & -18.9 \\
\hline$\Delta H^{\circ}$ Enthalpy $\left(\mathrm{kJ} \mathrm{mol}^{-1}\right)$ & -13.5 & -23.1 & -18.5 \\
\hline$\Delta S^{\circ}$ Entropy $\left(\mathrm{J} \mathrm{mol}^{-1} \mathrm{deg}^{-1}\right)$ & -12.9 & -0.9 & -1.2 \\
\hline Correlation coefficient $(r)$ & 0.9994 & 0.9998 & 0.9996 \\
\hline
\end{tabular}

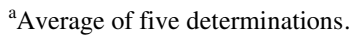

Bull. Chem. Soc. Ethiop. 2010, 24(1) 
Analytical parameters

Under the experimental conditions described, standard calibration curves of CT complexes for three amino acid derivatives were constructed by plotting absorbency intensity versus concentration. The data obtained from the linear regression equations are listed in Table 4. The correlation coefficients ranged from 0.9985 to 0.9996 , indicating good linearity. The small value of variance confirmed the small degree of scattering of the experimental data points around the regression line. The linear range was been determined by measuring the absorbance of each complex at its specific $\lambda_{\max }$.

Table 4. Quantitative parameters for CT complexes of studied drugs with TCNQ.

\begin{tabular}{|l|l|l|l|}
\hline Parameters & Carbocysteine-TCNQ & Aminobutyric acid-TCNQ & Levodopa-TCNQ \\
\hline$\lambda_{\max }(\mathrm{nm})$ & 422 & 415 & 417 \\
\hline Beer's law limits $\left(\mu \mathrm{g} \mathrm{mL}^{-1}\right)$ & $1-30$ & $1-10$ & $2-50$ \\
\hline Limit of detection $\left(\mu \mathrm{g} \mathrm{m}^{-1}\right)$ & 0.6 & 0.3 & 0.8 \\
\hline Intercept on the ordinate $(a)$ & -0.01761 & 0.11671 & -0.02198 \\
\hline Slope $(b)$ & 0.04585 & 0.12208 & 0.01216 \\
\hline $\begin{array}{l}\text { Molar absorptivity }(\varepsilon) \\
\left(\mathrm{L} \mathrm{mol}^{-1} \mathrm{~cm}^{-1}\right)\end{array}$ & $8.20 \times 10^{3}$ & $1.26 \times 10^{4}$ & $2.40 \times 10^{3}$ \\
\hline Correlation coefficient $(r)$ & 0.9996 & 0.9989 & 0.9985 \\
\hline Sandell sensitivity $\left.(\mu \mathrm{g} \mathrm{cm})^{-2}\right)$ & 0.021 & 0.008 & 0.082 \\
\hline
\end{tabular}

\section{Analytical application}

The proposed methods were applied to the determination of carbocysteine, $\gamma$-aminobutyric acid and levodopa in tablets containing the drugs. Five repeated determinations were made. Satisfactory results were obtained for three drugs (Table 5). Moreover, to check the validity of the proposed methods, the standard addition method was applied by adding the pure drugs to the previously analyzed tablets. The recovery of each drug was calculated by comparing the concentration obtained from the mixtures with those of the pure drugs. Table 5 shows the results of analysis of the commercial tablets and the recovery study (standard addition method) of three drugs. Comparison of the results obtained by the proposed method with those obtained by official method [5] and literature method [18, 30] showed satisfactory agreement.

Table 5. Determination of drugs in pharmaceutical formulations using TCNQ $(n=5)$.

\begin{tabular}{|l|c|c|c|}
\hline \multirow{2}{*}{ Drugs } & \multicolumn{2}{|c|}{ Present method } & Reference method \\
\cline { 2 - 4 } & $\begin{array}{l}\text { Equivalent nominal } \\
\text { content (\%) } \pm \text { S.D. }\end{array}$ & Recovery (\%) & $\begin{array}{l}\text { Equivalent nominal } \\
\text { content (\%) } \pm \text { S.D. }{ }^{\text {a }}\end{array}$ \\
\hline Carbocysteine & & & $100.16 \pm 0.66[18]$ \\
\hline Pure drug & $99.89 \pm 1.18$ & & $97.13 \pm 1.41[18]$ \\
\hline Tablet (250 mg) (I) & $97.40 \pm 0.65$ & $98.48 \pm 1.87$ & $97.24 \pm 1.48[18]$ \\
\hline Tablet (250 mg) (II) & $97.16 \pm 0.99$ & $99.95 \pm 1.11$ & \\
\hline Aminobutyric acid & & & $99.96 \pm 0.76[30]$ \\
\hline Pure drug & $100.12 \pm 0.86$ & & $97.70 \pm 1.49[30]$ \\
\hline Tablet (250 mg) (I) & $96.16 \pm 0.73$ & $101.80 \pm 1.19$ & $98.36 \pm 1.59[30]$ \\
\hline Tablet (250 mg) (II) & $97.74 \pm 0.67$ & $98.15 \pm 0.64$ & \\
\hline Levodopa & & & $99.92 \pm 1.34[5]$ \\
\hline Pure drug & $100.23 \pm 0.78$ & & $98.52 \pm 0.89[5]$ \\
\hline Tablet (250 mg) (I) & $97.83 \pm 1.30$ & $99.85 \pm 1.40$ & $102.34 \pm 1.56[5]$ \\
\hline Tablet (250 mg) (II) & $101.22 \pm 1.17$ & $102.80 \pm 1.21$ & \\
\hline
\end{tabular}

${ }^{\mathrm{a}}$ Average of five determinations with standard deviation.

Bull. Chem. Soc. Ethiop. 2010, 24(1) 
The high-absorbance bands and the very low reagent background absorbance make these procedures suitable for the routine quality control analysis of the investigated compounds with minimum interference. The proposed and reference methods were applied to the determination of the drugs in tablets containing different drugs (Table 5). The obtained mean values $( \pm$ S.D.) of the labelled amounts ranged from $96.16 \pm 0.73$ to $101.22 \pm 1.17$, the recoveries ranged from $98.15 \pm 0.64$ to $102.80 \pm 1.21$. In the $t$ - and $F$-tests, no significant differences were found between the calculated and theoretical values (95\% confidence) of both the proposed and reference methods. This indicates similar precision and accuracy between proposed and reference methods.

Precision of the proposed methods was determined in each concentration range, by eleven measurements carried out on different days within a week of different solution of studied drugs. Target concentrations corresponded to middle values of each range. Table 6 gives an RSD (within-day and between-day) of solutions of certain concentrations were determined by using the proposed procedure.

Table 6. Reproducibility of results obtained using of the proposed methods $(n=11)$.

\begin{tabular}{|l|c|c|c|}
\hline Drugs & Concentration $\left(\mu \mathrm{g} \mathrm{mL}^{-1}\right)$ & Within-day $\mathrm{RSD}^{\mathrm{a}}(\%)$ & Between-day RSD $^{\mathrm{a}}(\%)$ \\
\hline \multirow{3}{*}{ Carbocysteine } & 5 & 1.5 & 0.8 \\
\cline { 2 - 4 } & 15 & 0.7 & 1.0 \\
\cline { 2 - 4 } & 25 & 0.7 & 0.9 \\
\hline \multirow{3}{*}{ Aminobutyric acid } & 2 & 0.9 & 1.5 \\
\cline { 2 - 4 } & 5 & 1.4 & 1.8 \\
\cline { 2 - 4 } & 8 & 1.2 & 1.6 \\
\hline \multirow{3}{*}{ Levodopa } & 10 & 0.7 & 0.9 \\
\cline { 2 - 4 } & 25 & 0.9 & 1.5 \\
\cline { 2 - 4 } & 40 & 1.4 & 1.8 \\
\hline
\end{tabular}

${ }^{\mathrm{a}}$ Average of eleven determinations.

The assay result was unaffected by the presence of excipients as shown by the excellent recoveries obtained when analyzing the drugs in presence of commonly encountered excipients. As samples containing a fixed amount of the studied drugs $\left(5 \mu \mathrm{g} \mathrm{mL}^{-1}\right)$ and excipients $(50 \mu \mathrm{g}$ $\mathrm{mL}^{-1}$ ) were measured, no interference was observed from commonly used excipients such as starch, lactose, glucose, fructose, sucrose, and magnesium stearate. This fact indicates good selectivity of the method to determine the studied drugs both in raw material and in their dosage forms.

\section{CONCLUSIONS}

The results obtained from the present study indicate that $n-\pi$ CT complex formation between the amino acid derivatives and TCNQ was applied in the spectrophotometric assay of carbocysteine, aminobutyric acid and levodopa in its dosage forms. The proposed method can be used for the routine quality control of the pure drug and in tablets without fear of interference caused by the excipients expected to be present in tablets. The method has been also applied successfully to the determination of the active constituent in a commercial pharmaceutical. The proposed method has the advantages of easy operation, high recovery, speed, and minimal use of organic solvent. The investigation of real samples revealed the potential of the method in pharmaceutical analysis. 


\section{AKNOWLEDGEMENTS}

This research was supported by State Key Laboratory of Chemical Resource Engineering of China and the Natural Science Foundation of Shanxi Institution of Higher Education (No. 20080025).

\section{REFERENCES}

1. Roy, D.K.; Saha, A.; Mukherjee, A.K. Spectrochim. Acta A 2005, 61, 2017.

2. The British Pharmacopoeia Commission, British Pharmacopoeia (Ph. Eur. monograph 0885), Stationery Office: London; 2003.

3. The Committee on Japanese Pharmacopoeia Japanese Pharmacopoeia, 14th ed., The Ministry of Health, Labour and Welfare: Tokyo; 2001; p 310.

4. The Editorial Committee of the Pharmacopoeia of PR China, Pharmacopoeia of People's Republic of China (Part II), Chemical Industry Press: Beijing; 2005; p 817.

5. The United States Pharmacopeial Convention, U.S. Pharmacopeia, The United States Pharmacopeial Convention: Rockvill; 2005; p 1121.

6. The British Pharmacopoeia Commission, British Pharmacopoeia (Ph. Eur. monograph 0038), Stationery Office: London; 2003.

7. The Committee on Japanese Pharmacopoeia The Committee on Japanese Pharmacopoeia Japanese Pharmacopoeia, 14th ed., The Ministry of Health, Labour and Welfare: Tokyo; 2001; p 571.

8. The Editorial Committee of the Pharmacopoeia of PR China, Pharmacopoeia of People's Republic of China (Part II), Chemical Industry Press: Beijing; 2005; p 85.

9. Zaia, D.A.M.; Ribas, K.C.L.; Zaia, C.T.B.V. Talanta 1999, 50, 1003.

10. Li, S.-Y.; Ren, Y.-Z.; Zhao, F.-L. Chin. Chem. Lett. 2006, 17, 1065.

11. Taha, E.A.; Hassan, N.Y.; Aal, F.A.; Fattah, L.E.-S.A. J. Fluoresc. 2007, 17, 293.

12. Walash, M.I.; El-Brashy, A.M.; Metwally, M.E.-S.; Abdelal, A.A. Acta Chim. Slovenica 2004, 51, 283.

13. Kim, W.H.; Karim, M.M.; Lee, S.H. Anal. Chim. Acta 2008, 619, 2.

14. Lu, M.-J.; Chiu, T.-C.; Chang, P.-T.; Ho, H.-T.; Chang, H.-T. Anal. Chim. Acta 2005, 538, 143.

15. Lin, Y.-P.; Su, Y.-S.; Jen, J.-F. J. Agric. Food Chem. 2007, 55, 2103.

16. Zhao, S.; Bai, W.; Wang, B.; He, M. Talanta 2007, 73, 142.

17. Zhang, Y.-X.; Zhang, Z.-J.; Yang, F. Chin. J. Chem. 2008, 26, 489.

18. Argekar, A.P.; Raj, S.V.; Kapadia, S.U. Anal. Lett. 1997, 30, 821.

19. Eckstein, J.A.; Ammerman, G.M.; Reveles, J.M.; Ackermann, B.L. J. Neurosci. Meth. 2008, $171,190$.

20. Zhao, X.-E.; Suo, Y.-R. Talanta 2008, 76, 690.

21. Muzzi, C.; Bertocci, E.; Terzuoli, L.; Porcelli, B.; Ciari, I.; Pagani, R.; Guerranti, R. Biomed. Pharmacother. 2008, 62, 253.

22. Zhao, F.L.; Xu, B.Z.; Zhang, Z.Q.; Tong, S.Y. J. Pharm. Biomed. Anal. 1999, 21, 355.

23. Saleh, G.A.; Askal, H.F.; Radwan, M.F.; Omar, M.A. Talanta 2001, 54, 1205.

24. Salem, H. J. Pharm. Biomed. Anal. 2002, 29, 527.

25. Mulliken, R.S. J. Chim. Phys. 1939, 7, 20.

26. Du, L.M.; Yang, Y.Q.; Wang, Q.M. Anal. Chim. Acta 2004, 516, 237.

27. Foster, R. Organic Charge-Transfer Complexes, Academic Press: London; 1969; pp 51, 387.

28. Benesi, H.A.; Hidelbrand, J. J. Am. Chem. Soc. 1949, 71, 2703.

29. Person, W.B. J. Am. Chem. Soc. 1962, 84, 536.

30. Chinese State Drug Administration, State Drug Standard, WS1-XG-2002; 2002. 